\title{
Influence of structural defects on photoconductivity of zinc diphosphide
}

\author{
A.P. Kudin, V.I. Kuts, P.G. Litovchenko, M.B. Pinkovska, V.P. Tartachnyk \\ The Scientific Center Institute for Nuclear Research, National Academy of Sciences of Ukraine, 47 Pr. Nauky, 03028 Kyiv, Ukraine \\ E-mail: interdep@kinr.kiev.ua Fax: 380442654463
}

\begin{abstract}
Spectral distribution of photoconductivity of initial and gamma-irradiated $p$-type zinc diphosphide crystals of tetragonal modification has been studied.

It is supposed that band $h v=1.65 \mathrm{eV}$ responses to clusters of defects existing in initial crystals. Complex defects appearing during high temperature treatment $\left(400^{\circ} \mathrm{C}\right)$ form band $h v=1.55-2.14 \mathrm{eV}$.

Irradiation leads to the decrease of dark current and appearing of acceptor type level which can be annealed in the temperature interval $20-100^{\circ} \mathrm{C}$.
\end{abstract}

Keywords: radiation defects, $\gamma$-irradiation, photoconductivity.

Paper received 26.01.01; revised manuscript received 05.03.03; accepted for publication 13.07.01.

\section{Introduction}

It is known that initial technology defects of vacancy type influence strongly on the conductivity type and carrier concentration in $\mathrm{ZnP}_{2}$ [1]. Radiation also changes semiconductor properties. Thus, defects introduced by high energy electrons may be effective centers of positron capture [2]. They cause the increase of the electroconductivity at low temperature irradiation $(77 \mathrm{~K})$ and its decrease at irradiation temperature $300 \mathrm{~K}$ [3]. They are also stoppers for the dislocation movement and increase the crystal microhardness, too [4].

But in general, most of works that deal with penetrating radiation influence on zinc diphosphide crystals are qualitative and do not clear up the nature of structural defects and their role in forming of characteristics of initial and irradiated devices.

In the present article, results of the study of stationary photoconductivity of gamma-irradiated $\alpha-\mathrm{ZnP}_{2}$ samples are given. An attempt is made to find out the depth of defect levels and to study transition mechanisms which form main photoconductivity spectra bands of initial and irradiated $\alpha-\mathrm{ZnP}_{2}$ crystals.

\section{Experiment and results}

For these studies $p$-type $\alpha-\mathrm{ZnP}_{2}$ single crystals of tetragonal modification were used. They were grown from the vapor phase by the stationary re-sublimation technique. The ohmic contacts were made by the gold dusting with the subsequent burning in vacuum at $400^{\circ} \mathrm{C}$. Irradiation by $\gamma$-quanta of ${ }^{60} \mathrm{Co}$ was held at room temperature up to dose $3 \cdot 10^{7} \mathrm{~Gy}$. Photoconductivity at room and nitrogen temperatures was measured on the basis of monochromator SPM-I. The period of isochronal annealing for initial and irradiated samples was $15 \mathrm{~min}$.

It was found that the photocurrent spectral dependence $I_{p h}(\lambda)$ of initial samples at room temperature has the maximum at $h v=2.3 \mathrm{eV}$ and the unstructured gentle slope at the region $h v<2 \mathrm{eV}$ (Fig. 1). At the nitrogen temperature the absolute maximum is divided onto two peaks at $h v=2.21 \mathrm{eV}$ and $h v=2.53 \mathrm{eV}$.

The model of zinc diphosphide band structure obtained, using the group-theory calculation method, has shown that this semiconductor belongs to compounds with «indirect» forbidden gap $[5,6]$. Taking into account the temperature band displacement one may conclude from the comparison of $\mathrm{ZnP}_{2}$ peak locations with the band diagram the indirect transitions from the lower valence band $V_{3}$ to conduction subband $\mathrm{C}_{1}$ must correspond to the photoconductivity maximum at $h v_{1}=2.21 \mathrm{eV}$. The second higher energy maximum $h v_{2}=2.54 \mathrm{eV}$ seems to be connected with direct fundamental transitions $V_{1}-C_{3}$ and surface photoconductivity. At the impurity photoconductivity region $h v<2 \mathrm{eV}$ the sharp threshold $h v=1.38 \mathrm{eV}$ and the broad band from 1.44 to $1.74 \mathrm{eV}$ with the maximum $h v=1.67 \mathrm{eV}$ occur at $77 \mathrm{~K}$. The annealing of ini- 


\section{A.P. Kudin et al.: Influence of structural defects on photoconductivity ...}

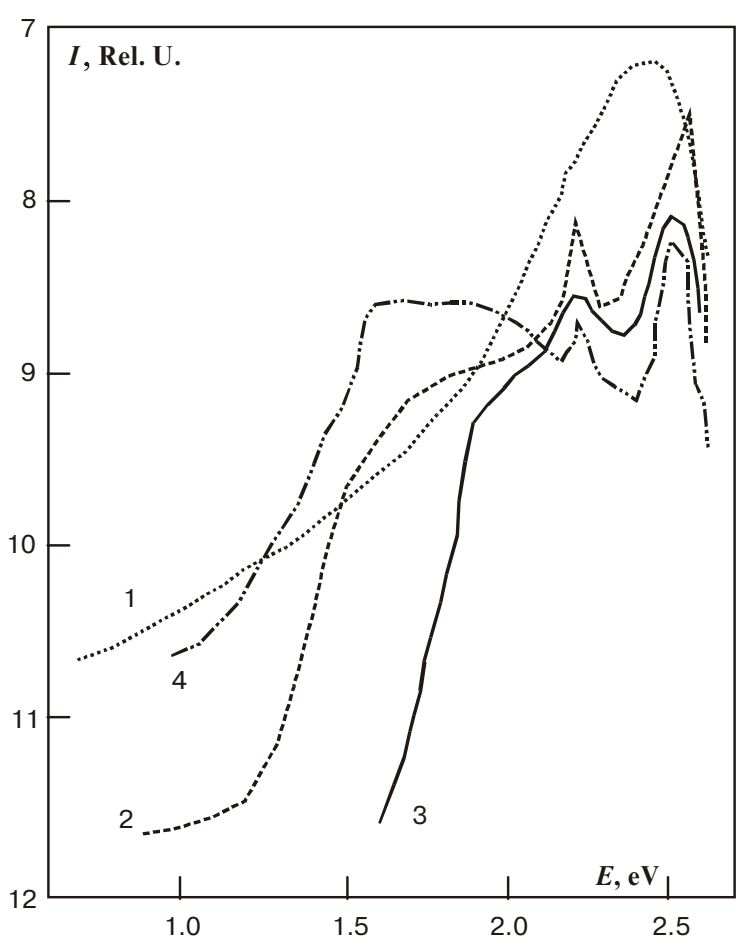

Fig. 1. Spectral dependences of photocurrent of $\alpha-\mathrm{ZnP}_{2}$ crystals for the initial $(1,2)$ and annealed samples at $T=120 \cdot \mathrm{C}(3), T=$ $=400^{\circ} \mathrm{C}(4)$. Temperatures of measurements were $300 \mathrm{~K}(1)$ and $77 \mathrm{~K}(2,3,4)$.

tial crystals at $120^{\circ} \mathrm{C}$ causes the photoconductivity decrease in the above interval, disappearance of the structure and the photoconductivity increase in near edge ranges, where weak intensity band $h v=1.94 \mathrm{eV}$ is observed.

Taking into account that simple defects such as separate vacancies and interstitial atoms can be annealed at temperatures beneath $300 \mathrm{~K}$ [3], the sharp increase of photoconductivity with the threshold $h v=1.38 \mathrm{eV}$ and the band $h v=1.67 \mathrm{eV}$ seems to be connected with initial technology defects of the point defect cluster type. More likely, there are electron traps located at $E_{v}+1.38 \mathrm{eV}$ and the system of continuous levels in the range $1.44-1.74 \mathrm{eV}$ from the top of $V$-band.

It is necessary to mention that for all crystals the appearance of the broad band $h v=1.55-2.14 \mathrm{eV}$ after the high temperature annealing $\left(400^{\circ} \mathrm{C}\right)$ correlates with the photoconductivity increase at the whole quantum energy interval. Concerning the nature of this band one may consider:

it has been shown earlier that the long high temperature annealing $\left(500^{\circ} \mathrm{C}\right)$ increases free hole concentration and the mobility of carriers in $\mathrm{ZnP}_{2}$ crystals. From the results received after crystal annealing in the vapor of components the authors have decided that the conductivity increase was caused by the decrease of vacancy defects [1]. But later, when the method of the positron annihilation on $\mathrm{ZnP}_{2}$ defects was used, the increase of the intensity of narrow component of the annihilate irradia-

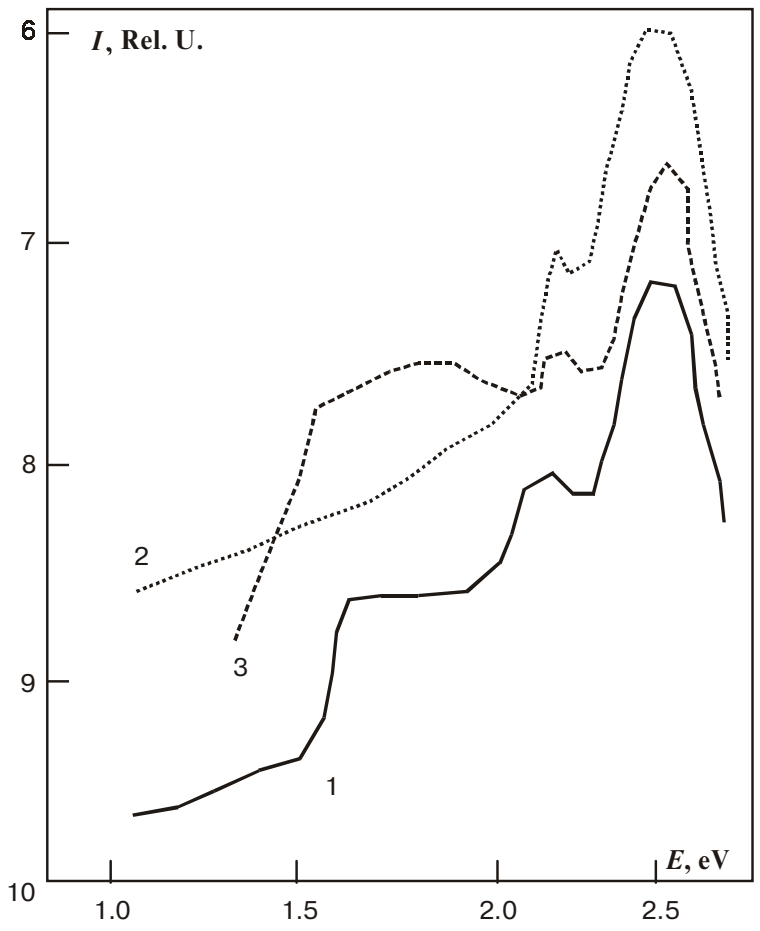

Fig. 2. Spectral dependences of photocurrent of $\alpha-\mathrm{ZnP}_{2}$ crystals affer $\gamma$-irradiation up to dose of $\Phi=3 \cdot 10^{9} \mathrm{~Gy}$ (1) and annealed at $60^{\circ} \mathrm{C} \mathrm{(2),} 400^{\circ} \mathrm{C}(3)$. The temperature of measurements was $77 \mathrm{~K}$.

tion after $400{ }^{\circ} \mathrm{C}$ annealing has been found [2]. This definitely indicates on the crystal «enrichment» by the negative vacancies. Hence, it is obvious that defects of the complex vacancy type which seems to occur due to evaporation during temperature treatment of one of the volatile component (the most probably, of phosphorus) are involved in the formation of the band. Therefore, the photoconductivity increase at the range $h v=1.55-2.14 \mathrm{eV}$ one can interpret as electron upward transition from the defect level followed by the capture of the valence band electron on a free place, because the negatively charged defect level must be located lower than the Fermi level.

${ }^{60} \mathrm{Co} \gamma$-irradiation of the $\mathrm{ZnP}_{2}$ crystals up to doses $3 \cdot 10^{7} \mathrm{~Gy}$ leads to the decrease of dark photocarrent approximately to one order of magnitude comparatively to the photocurrent of non-irradiated samples.

The change multicipities $I_{h}(h v)$ under the illumination in the maximum sensitivity region are $10^{3}$ and $10^{5}$ for non-irradiated and irradiated crystals, respectively.

The activation energy of dark conductivity received from the slope of curve $\sigma(T)$, is equal $E=0.5 \mathrm{TeV}$. It does not depend on irradiation doze and annealing temperature. This fact indicates that the radiation induced levels are deep.

The sharp threshold at $h v=1.5 \mathrm{eV}$ occurs on the dependence $I_{h}(h v)$ of irradiated samples. It disappears after $60^{\circ} \mathrm{C}$ annealing (Fig. 2). So in the temperature interval $20-100^{\circ} \mathrm{C}$ there may be another acceptor defect with the location depth $E_{c}-0.5 \mathrm{eV}$, unnoticed earlier by electroconductivity annealing of $\mathrm{ZnP}_{2}$ [3]. It was found 


\section{A.P. Kudin et al.: Influence of structural defects on photoconductivity ...}

from experimental curve that intensity of $h v=2.21 \mathrm{eV}$ band in irradiated crystals increases in comparison with the $h v=2.5 \mathrm{eV}$. This may be connected with the increase of probability of indirect transitions in radiation fields.

\section{Conclusions}

The results received from photoconductivity measurements for tetragonal zinc diphosphide crystals implies that absorbed photons with energy $h v=2.21 \mathrm{eV}$ correspond to the transition from valence band to the upper conduction subband $C_{1}$. Transitions $h v=2.54 \mathrm{eV}$ are direct transitions $V_{1}-C_{3}$, and the broad unstructural surface photoconductivity is exposed on it. The impurity photoconductivity occurs at the boundaries $h v=1.44-1.74 \mathrm{eV}$ with the maximum $h v=1.67 \mathrm{eV}$. The main part of defects, connected with this band, disappear at annealing up to $120^{\circ} \mathrm{C}$. Complex vacancy defects, more likely the phosphorous ones, participate in the forming of $h v=1.55-2.14 \mathrm{eV}$ band.

Radiation defects caused by gamma irradiation of ${ }^{60} \mathrm{Co}$ correspond to deep levels. As a consequence, the probability of indirect transitions increases.

\section{References}

1. I.S Gorban', G.A.Grishchenko, A.P Sacalas, A.S. Sodeika, I.I. Tychina, A.K. Tkachenko Electrical Properties of $\mathrm{ZnP}_{2}$ Single Crystals of Tetragonal and Monoclinic Modification $/$ I Phys. stat. sol.(a), 48, pp. 329-334 (1978).

2. A.P. Kudin, Investigation of irradiated $\alpha-\mathrm{ZnP}_{2}$ crystal defect structure evolution using the positron annihilation method and study of micromechanical parameter kinetics //Herald of the state university «L'vivs'ka politekhnika» (in Ukrainian), №367, pp. 13-18 (2000).

3. Z. Januskevicius, V. Koval, A. Kudin, A. Sodeika, V Tartachnik, I. Tychina. Radiation defects in Single Crystals of Zinc Diphosphide // Phys. Stat. Sol.(a), 81, pp. K191 (1984).

4. A.S.Poverennykh, A.Yu. Gerasimov, A.P. Kudin, I.S. Magela, V.P. Tartachnik, Microhardness of irradiated GaP and $\mathrm{ZnP}_{2}$ (in Russian)//Doklady Akademii nauk Ukrainskoi SSR, ser.B, №6, pp. 21-24 (1984).

5. V.Sobolev, N.Syrbu, T.Suschkevich, Energy Band Structure of the Tetragonal Crystals $\mathrm{ZnP}_{2}$ and $\mathrm{Cd}_{2} / /$ Phys. stat. sol.(b), 43, pp. 73-81 (1971).

6. V.A.Zuyev, V.G. Popov, B.N. Romanyuk, Condenser photoe.m.f. in ion-bombarded crystals $\mathrm{ZnP}_{2}$ and $\mathrm{CdP}_{2}$ (in Russian) // Poverkhnost'. Phisika, khimiya, mekhanika, №7, pp. 9497 (1992). 